\title{
O uso da aprendizagem baseada em problemas para construção do conhecimento na contabilidade
}

\author{
The Use of Problem-Based Learning in the Construction of Knowledge in Accounting \\ El uso del aprendizaje basado en problemas en la construcción del conocimiento en \\ ciencias contables
}

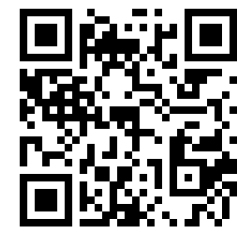

Recibido • Received • Recebido: 29 / 08 / 2018

Corregido • Revised • Revisado: 06 / 02 / 2020

Aceptado • Accepted • Aprovado: 05 / 04 / 2020

\begin{abstract}
Resumo: O conhecimento, na visão piagetiana, é visto como um elemento fruto da interação do sujeito com o meio, compreendendo o sujeito como um ser fundamental que participa do processo de construção do seu conhecimento ativamente. De maneira semelhante, a aprendizagem baseada em problemas é uma técnica de ensino que impõe responsabilidade aos estudantes no processo de construção do conhecimento. Neste sentido, este estudo buscou verificar como uma metodologia ativa, especificamente a aprendizagem baseada em problemas, pode auxiliar na assimilação do conteúdo, contribuindo com a construção do conhecimento. Para tanto, foi realizada uma pesquisa qualitativa, através de um estudo de caso, com estudantes do $4^{\circ}$ semestre de Ciências Contábeis, matriculados na disciplina Estrutura das Demostrações Contábeis, em uma Instituição de Ensino Superior Federal. A técnica da aprendizagem baseada em problemas foi utilizada no processo de ensino-aprendizagem do conteúdo Demonstração do Valor Adicionado (DVA). Os resultados apontam que, de forma geral, o uso da aprendizagem baseada em problemas colabora positivamente para assimilação do conteúdo. Na primeira avaliação realizada, após a aula expositiva seguida de resolução de exercício, constatou-se que $58,62 \%$, dos estudantes assimilaram o conteúdo, e após a aplicação da técnica, esta assimilação passou
\end{abstract}

Michele Urrutia-Heinz, Alexandre Costa-Quintana y Ana Paula Capuano-da Cruz 
http://doi.org/10.15359/ree.24-2.19

ROR: https://ror.org/01t466c14 Universidad Nacional, Costa Rica

http://www.una.ac.cr/educare

educare@una.cr

para 95,23\%, revelando que o uso desta técnica de aprendizagem baseada em problemas é impactante para a construção do conhecimento, além de proporcionar benefícios como trocas de experiências, simulação de uma situação real e desenvolvimento de habilidades como procurar soluções.

Palavras chaves: Aprendizagem baseada em problemas; construção do conhecimento; construtivismo; pensamento piagetiano.

\begin{abstract}
From the Piagetian perspective, knowledge is seen as an element resulting from the interaction between subject and the environment, understanding the subject as a fundamental being that participates in the process of constructing knowledge actively. Likewise, problem-based learning is a teaching technique, which imposes on the student the responsibility for his / her knowledge. In this sense, this study sought to verify if the use of an active methodology, specifically problem-based learning, can help in the assimilation of knowledge. For that, qualitative research was conducted through a case study, with students of the 4th semester of Accounting Sciences, enrolled in the Accounting's Structure Statements program, in a federal higher education institution. The technique of problem-based learning was used in the teaching-learning process of the Demonstration of Added Value content (DVA). The results show that, in general, the use of problem-based learning for content assimilation is significant, since in the first evaluation, after the lecture, over $58,62 \%$ of the students assimilated the content. After applying the technique, the assimilation rose to $95.23 \%$, revealing that the use of this technique is impressive for the construction of knowledge, besides providing benefits such as the exchange of experience, simulation of a real situation, and development of abilities such as the search for solutions.
\end{abstract}

Keywords: Problem-based learning; knowledge; constructivism; piagetian thought.

Resumen: El conocimiento, en la visión piagetiana, es visto como un elemento fruto de la interacción del sujeto con el medio, comprende al sujeto como un ser fundamental que participa activamente del proceso de construcción de su conocimiento. De manera similar, el aprendizaje basado en problemas es una técnica de enseñanza que impone responsabilidad al alumnado en el proceso de construcción del conocimiento. En este sentido, este estudio buscó verificar cómo una metodología activa, específicamente el aprendizaje basado en problemas, puede auxiliar en la asimilación del contenido, al contribuir con la construcción del conocimiento. Para ello, se realizó una investigación cualitativa, a través de un estudio de caso, con estudiantado del cuarto semestre de Ciencias Contables, matriculado en la disciplina Estructura de los Estados Contables, en una institución de enseñanza superior federal. La técnica del aprendizaje basado en problemas se utilizó en el proceso de enseñanza-aprendizaje del contenido de Demostración del Valor Agregado (DVA). Los resultados apuntan que de forma general, el uso del aprendizaje basado en problemas colabora positivamente para la asimilación del contenido. En la primera evaluación realizada, después de la clase expositiva seguida de resolución de ejercicio, se constató que 58,62 \%, de estudiantes asimila el contenido, y después de la aplicación de la técnica, esta asimilación pasó al 95,23\%, revelando que el uso de la técnica del aprendizaje basado en problemas es impactante para la construcción del conocimiento, además de proporcionar beneficios como intercambios de experiencias, simulación de una situación real y desarrollo de habilidades, tales como la búsqueda de soluciones.

Palabras claves: Aprendizaje basado en problemas; construcción del conocimiento; constructivismo; pensamiento piagetiano. 


\section{Introdução}

Na visão da teoria empirista o conhecimento é visto como algo que pode ser transmitido para o aluno, portanto, nela entende-se que o professor ensina e o aluno aprende (Becker, 2016). Porém, para Piaget (1990), o conhecimento é um processo histórico, que é resultado da evolução do sujeito, ou seja, é construído a partir das interações entre o sujeito e o mundo, através de experiências. Neste contexto, o sujeito é entendido como um ser ativo, dotado de de iniciativa, processos cognitivos, e consciência, sendo assim, um ser capaz de aumentar sua capacidade, extraindo das próprias ações novas possibilidades (Becker, 2016). Deste modo, para Piaget (1990) o conhecimento é fruto de uma construção, que utiliza mecanismos mentais para traduzir o mundo, e por isso não pode ser transferido, pois é consequência da informação incorporada, assimilada pelo sujeito durante todas as etapas de sua vida, a partir da interação que teve, tem e terá com o externo.

Com base no exposto, esta pesquisa parte da premissa que o conhecimento é considerado como um processo no qual uma informação é adquirida e questionada, até que surjam novos argumentos que alterem aquela constatação realizada inicialmente. Nessa dinâmica de construção do conhecimento, a epistemologia busca conhecer e analisar todas as etapas de sua estruturação (Japiassu, 1992). O autor complementa que, por existir um ciclo de constatação e questionamento, o conhecimento é sempre provisório, nunca definitivo, pois se encontra em constante evolução.

Neste cenário, o papel das Instituições de Ensino deve ser o de preparar o estudante para que ele possa desenvolver habilidades e competências, estabelecendo relações significativas com o universo (Moretto, 2003). Para atingir este objetivo, o autor entende que é preciso transformar a interação em sala de aula em ação, proporcionando reflexões construtivistas.

Contribuindo com esse pensamento, Freire (1996, p. 47) afirma que "ensinar não é transferir conhecimento, mas criar as possibilidades para a sua produção ou sua construção", enfatizando que o professor que utiliza o método de memorização intimida a curiosidade e a liberdade do educando. Assim, o papel do docente na visão construtivista deve ser de mediador, escolhendo materiais para a sala de aula que proporcionem ao aluno explorar e construir um novo conhecimento (Becker, 2016). Para Piaget (1970), mesmo ocorrendo de maneira espontânea, a educação obedece critérios sociológicos que podem ser analisados, servindo de base para reflexões sobre o processo educativo.

O uso de metodologias ativas pode contribuir com o processo de aprendizagem utilizando concepções construtivistas, como um procedimento de ação-reflexão-ação, em que o estudante posiciona-se de maneira ativa em relação ao seu aprendizado, vivenciando a prática através da resolução de um problema, estimulando a procura por soluções possíveis de serem aplicadas à realidade (Freire 1996). O método de aprendizagem baseado em problemas $(\mathrm{ABP})$, também conhecido por Problem Based Learning (PBL), é uma metodologia ativa em que o 
ensino é centrado no aluno, focando na discussão e resolução de problemas, que proporcionam o aprendizado mais profundo e significativo ao estudante (Leal et ál., 2017).

Diante da discussão de que o conhecimento é construído e o papel do professor deve ser mediar e proporcionar esta construção, define-se a seguinte questão para esta pesquisa: Como o uso da aprendizagem baseada em problemas pode auxiliar na construção do conhecimento?

Para responder a esse questionamento, esta pesquisa tem como objetivo verificar se o uso da técnica de aprendizagem baseada em problemas pode auxiliar na assimilação do conteúdo, contribuindo com a construção do conhecimento, à luz da Teoria da Equilibração.

Identificar possíveis caminhos que contribuam para assimilação do conteúdo é certamente um produto muito importante à academia, isso porque, trata-se de uma demanda cada vez mais presente nos dias atuais. Sabe-se que as gerações mais novas têm preferências distintas daquelas manifestadas pelos estudantes de 20 anos atrás. Dessa forma, compreender o papel da Aprendizagem baseada em Problemas no processo de construção do conhecimento é fundamental para que os docentes possam investir no uso de metodologias mais alinhadas às preferêncais discentes.

Este artigo está estruturado em 5 seções. A seção introdutória contextualiza a contrução do conhecimento na visão de Piaget e apresenta a questão investigada. A seguir, a seção 2 apresenta a revisão da literatura de base, contemplando a Teoria da Equilibração Piagetiana, o ensino e a aprendizagem sob a ótica construtivista, a Aprendizagem baseada em Problemas e, por um, Estudos anteriores. A seguir, na seção 3 são descritos os procedimentos metodológicos empregados. Na sequência, a seçã 4 reúnce a análise e discussão dos resultados e, por fim, a seção 5, as considerações finais do estudo.

\section{Revisão teórica}

\section{Teoria da Equilibração Piagetiana}

Desenvolvida por Jean Piaget, a Teoria da Equilibração apresenta uma perspectiva construtivista sobre o processo de ensino e aprendizagem, enfatizando que os aprendizes vão construindo suas representações mentais a partir do mundo que vivenciam (de Carvalho et ál., 1992). Assim, Piaget buscou compreender o processo de desenvolvimento humano, elaborando estruturas de análise a partir da inteligência e de seus fundamentos (de Matos, 2008).

Buscando distinguir a inteligência do pensamento, Piaget (1970) apresenta como função essencial da inteligência às ações de compreender e inventar, construindo estruturas para definir o real e elaborar uma estrutura própria de compreensão. Esta inteligência, para o autor, é uma adaptação, caracterizada como um equilíbrio entre as ações do organismo sobre o meio. 
Já o conhecimento, decorre da ação, não meramente através de uma simples associação, mas por meio de uma associação profunda do real, onde conhecer um objeto é assimilar o real às estruturas de transformações e a partir da inteligência, efetuar e coordenar as ações de maneira reflexiva e interiorizada (Piaget, 1970). Deste modo, o processo de adaptação diz respeito à interação do sujeito com o meio em que vive, proporcionando uma modificação em seu organismo (de Matos, 2008).

Portanto, para compreender como o conhecimento surge e se forma no ser humano, a partir das interações do indivíduo, Piaget defende que o conhecimento não pode ser vislumbrado apenas através das estruturas mentais do sujeito, pois ele é resultado de um processo contínuo em construção (Rosa, 1996). Desta maneira, segundo o autor, para Piaget só existe conhecimento porque existe uma construção por parte do sujeito, resultante de sua evolução, onde cada etapa vivenciada adquire um desenvolvimento alicerçado em um anterior, possibilitando a formação de novas estruturas.

Apesar de o desenvolvimento apresentar uma mesma sequência para todos os indivíduos, Rosa (1996) salienta que a cronologia varia de pessoa para pessoa, pois cada ser humano tem maturações e experiências diferentes e a partir delas constrói seu conhecimento. Assim, ao agir sobre o mundo e sobre o outro, o sujeito alimenta sua transformação (Becker, 2016). Destaca-se que neste processo evolutivo da mente, existem elementos invariantes funcionais, como a organização, a assimilação e a acomodação, onde a organização é apresentada como um conjunto associado de entidades organizadas, que compõem uma estrutura, usada para interação do sujeito com a realidade (Rosa, 1996).

Segundo Piaget (1970), as interações são construídas a partir de Esquemas; espécies de unidades estruturais do pensamento ou da ação, que correspondem a uma estrutura que muda e se adapta, ou seja, a ação é associada a uma sequência de ações que se referem a um todo organizado. A partir das ações interiorizadas decorrem os processos de transformações, que por meio de operações lógicas ou matemática resultam na inteligência, definida como "uma assimilação do dado às estruturas de transformações, das estruturas das ações elementares às estruturas operatórias superiores, e que essas estruturas consistem em organizar o real em ato ou em pensamento - e não apenas em, simplesmente, copiá-las" (Piaget, 1970, p. 30).

Quanto à assimilação, ela ocorre quando determinada informação é reunida às estruturas pré-existentes, passando a coexistir a estrutura cognitiva, enquanto que a adaptação se apresenta quando o organismo se modifica e incorpora uma nova informação (Piaget, 1987). Desta maneira, o processo de assimilação, se refere à forma como cada sujeito interage com o mundo e procura superar ou acomodar uma nova informação, por meio de uma acomodação, que é essencial para a própria adaptação (Rosa, 1996). Neste processo, de interação entre assimilação e acomodação, são constituídos os esquemas que se adaptam ou não a realidade, permitindo a assimilação. 
http://doi.org/10.15359/ree.24-2.19

ROR: https://ror.org/01t466c14 Universidad Nacional, Costa Rica

http://www.una.ac.cr/educare

educare@una.cr

Quando a adaptação encontra um equilíbrio entre os processos de assimilação e acomodação, tem-se a inteligência, ou seja, é esta assimilação que absorve todos os fatos de uma experiência, permitindo ao sujeito formar estruturações na qual incorpora a realidade exterior à suas atividades (Piaget, 1987). Para Piaget (1970, p. 155), "o pensamento é adaptado a uma realidade particular quando ele conseguiu assimilar aos seus próprios quadros essa realidade". Neste sentido, para o autor a medida em que a assimilação vai combinando-se com a adaptação, forma-se uma atividade dedutiva, e desta relação de dedução e experiência é caracterizada a razão.

A terceira invariante funcional apresentada pela teoria de Piaget refere-se ao processo de acomodação, que ocorre quando a estrutura se modifica, possibilitando a absorção de uma nova informação, onde aquisição do conhecimento se dá através da relação sujeito/objeto, de maneira mútua e progressiva (Rosa, 1996). Neste contexto, a vida é entendida como uma busca progressiva do equilíbrio entre essas formas e o meio, através da adaptação do organismo (Munari, 2010).

De acordo com Piaget (1975), tudo que se aprende através da existência e descrição dos agrupamentos é um pensamento que atingiu um equilíbrio. Segundo o autor, a partir das operações lógicas, a inteligência constitui-se de um equilíbrio; um estado que o organismo vive buscando atingir para sobreviver (Rosa, 1996).

No entanto, quando um esquema não absorve uma determinada situação externa apresentada, esta circunstância gera uma situação de desequilíbrio, que segundo Rosa (1996) encaminha o sujeito a um processo de acomodação da sua estrutura cognitiva ou não assimilação de um dado externo. Assim, de acordo com Rosa (1996), esta situação proporciona ao sujeito sua permanência no esquema em que se encontrava, antes da apresentação de uma nova situação.

Neste contexto, quando o sujeito é posto junto a uma situação externa, que lhe causa desequilíbrio, é através dos esquemas que pode realizar uma adaptação, incluindo uma nova informação a sua estrutura, ou seja, permitindo que ele assimile um novo conhecimento, que passará a coexistir junto a sua estrutura cognitiva (Piaget, 1970). Caso esta adaptação não ocorra, este sujeito, segundo o autor, permanecerá acomodado a sua estrutura anterior.

Segundo Libâneo (2014) não existe ensino sem que os alunos desenvolvam suas capacidades e habilidades mentais, ou seja, sem que assimilem ativamente os conhecimentos. Assim, Piaget (1970) defende que quando pretende-se formar indivíduos capazes de realizar progressos, deve-se promover uma educação baseada no descobrimento ativo da verdade, não imposta através de verdades estabelecidas mediante procedimentos de repetição. 


\section{Ensino e aprendizagem sob a ótica construtivista}

Na visão de Piaget (1970), a educação é uma condição necessária ao desenvolvimento natural. No entanto, o autor chama a atenção para a necessidade do pleno desenvolvimento das funções mentais e da aquisição dos conhecimentos, que levam até a adaptação.

De acordo com Rosa (1996), embasado na Teoria da Equilibração de Piaget, emergiu um movimento que procurou conectar a teoria piagetiana ao ambiente escolar, nomeado de Construtivismo, buscando implantar uma visão construtivista no processo educacional. Segundo Becker (1992), o que Piaget defende é que o sujeito e objeto se constituiem mutuamente através da interação, portanto, eles se constrõem.

Moretto (2003, p. 43) apresenta o construtivismo como uma corrente que busca construir uma teoria de conhecimentos coerentes, que "parte do observador que constrói ou inventa a realidade com a qual ele estabelece uma correlação dialética por intermédio da experiência". Neste sentido, o construtivismo reconhece a aprendizagem como um processo de construção de conhecimento, que se baseia na experiência (Jumaat et ál., 2017). Para Dewey (1910), a educação depende da ação, portanto a experiência é importante, pois é através dela que o aluno se torna capaz de atribuir significado e construir seu próprio entendimento.

Segundo Moraes (2000), esta corrente de pensamento é entendida como uma forma de reflexão na ação sobre a ação, compreendendo que a aprendizagem e o ensino são construídos pelos indivíduos. Segundo o autor existem vários modos de caracterizá-lo, apontando que no modelo de Piaget, a concepção de aprender se refere ao processo individual, através das estruturas lógicas ou cognitivas.

Assim, alguns postulados são utilizados de base para o Construtivismo:

(i) Não devemos supor a existência de um mundo exterior independente do observador, para levar em conta a atividade daquele que observa; (ii) A realidade é construída (inventada) pelo sujeito cognoscente; ela não é um dado pronto para ser descoberto; (iii) Os conhecimentos não são uma descrição da realidade dada, mas uma representação que dela construímos, construção esta cuja função é adaptativa, isto é, permite ao indivíduo prever as regularidades e assim viver num mundo de limitações, representado pelo mundo das coisas. (Moretto, 2003, p. 43)

O que Piaget (1970), expressa é que a educação deixe de ser um processo de transmissão de conhecimento, que apresenta verdades prontas aos estudantes, passando a focar na pesquisa e no esforço. Neste sentido, o autor sugere que através de métodos ativos, que utilizem a experimentação e proporcionem liberdade de iniciativa, possam gerar benefícios como compreensão, produção e criação, sem apenas gerar repetição. 
http://doi.org/10.15359/ree.24-2.19

ROR: https://ror.org/01t466c14 Universidad Nacional, Costa Rica

http://www.una.ac.cr/educare

educare@una.cr

Na visão da educação construtivista, de acordo com Moretto (2003), a relação que ocorre entre o professor e o aluno se dá por meio de uma interação, de maneira que o professor atue como um mediador entre o aluno e o conhecimento que este irá construir. Este método, para o autor, compreende a aprendizagem como um conceito de significância, de forma que a aprendizagem perpassa a simples memorização (Moretto, 2003). "A atitude sócio-construtivista significa entender que a aprendizagem é resultado da relação ativa sujeito-objeto, sendo que $a$ ação do sujeito sobre o objeto é socialmente mediada" (Libâneo, 2014, p. 2).

Portanto, segundo o autor, a função do docente, além de ser "portador" de conhecimentos, é estimular essa interação necessária aos alunos.

Neste contexto, a apropriação do conhecimento é acompanhada por um processo, que de acordo com Rosa (1996), deve: considerar os conhecimentos prévios do estudante; compreender que a educação é centrada no estudante; a aprendizagem ocorre através do envolvimento ativo do aluno; o conhecimento científico é visto como uma construção; e sua abordagem visa alterar diversos aspectos da educação em ciências.

\section{Aprendizagem baseada em problemas}

A técnica da aprendizagem baseada em problemas, também conhecida por Problem Based Learning, ou PBL, foi originada no Canadá, na década de 1960, através da escola de medicina e, segundo da Silva (2015), teve a intenção de dar uma resposta ao tédio e a insatisfação dos estudantes com as aulas exclusivamente expositivas. Esta técnica surgiu baseando-se em uma técnica semelhante, utilizada nos Estados Unidos, na escola de Direito, que usava o método de casos para empregar problemas do mundo real aos estudantes, com a intenção de provocar e motivar a aprendizagem (da Silva, 2015).

Da medicina o PBL expandiu-se para os demais cursos e um dos seus fundamentos baseiase na concepção de que ensinar o aluno é fazer com que ele aprenda através da busca pelo conhecimento (Leal et ál., 2017). Na visão de Schmidt (1983), a aplicação do PBL em pesquisas de ensino é promissora, visto que as pessoas aprendem de maneiras diferentes, permitindo, deste modo, aos alunos a escolha sobre o direcionamento de sua própria aprendizagem. Para que as potencializades da técnica sejam exploradas, o processo de ensino deve levar em consideração o contexto no qual o estudante está inserido e seu estilo de aprendizagem, visto que uns aprendem por mecanismos auditivos, alguns por imagens e outros aprendem praticando, ou seja, diferentes características do individuo justificam o uso de diferentes técnicas de ensino (Leal et ál., 2017).

Neste sentido, o PBL se baseia na apresentação de um problema elaborado segundo uma situação real, o qual se diferencia dos demais métodos, pois sua aplicação proporciona ao 
estudante trabalhar em grupo e desempenhar diferentes papéis, buscando-se assim, aproximálo, de fato, de uma situação profissional (Leal et ál., 2017).

Stanley e Marsden (2012) destacam que, apesar de pouco utilizada na área de contabilidade, a Aprendizagem baseada em Problemas apresenta benefícios como o desenvolvimento de habilidades de questionamento, trabalho em equipe e resolução de problemas, podendo desta forma, provocar mudanças que permitam melhorar os resultados de aprendizagem. Segundo Hendry et ál. (2017), a partir da aplicação do PBL, os alunos são encorajados a resolver problemas como se estivessem na posição de profissionais, apontando como um fator crítico a este processo, a ativação do conhecimento prévio. Os autores salientam que a função do docente neste processo é agir como facilitador, estimulando ações de investigação, que permitam a construção de novos conhecimentos.

\section{Estudos anteriores}

Rodrigues e Araujo (2007) realizaram pesquisa empírica em uma disciplina de Contabilidade ofertada em um curso de Administração, dividindo os estudantes em dois grupos, submetendo-os a técnica do PBL. Os autores concluiram que a técnica estimula o aprendizado, segundo a visão destes estudantes. A análise indicou que do grupo $A, 47 \%$ preferem o uso do $\mathrm{PBL}$, enquanto, que para $50 \%$ ele é indiferente, já para o grupo $\mathrm{B}, 34 \%$ preferem o $\mathrm{PBL}, 24 \%$ preferem o método tradicional e para $41 \%$ seu uso é indiferente.

A pesquisa de campo realizada por Frezatti et ál (2016), aplicou o PBL nos alunos formandos, de uma instituição pública de ensino superior, durante a disciplina de contabilidade gerencial. Os resultados demonstraram que o uso do $\mathrm{PBL}$ contribuiu para integrar o ensino à pesquisa e a prática.

O estudo de Caron e Bolsanello (2017) investigou as concepções de estudantes que cursam medicina, a respeito da aprendizagem desenvolvida na disciplina de semiologia, que adota, de maneira adaptada, o método de Aprendizado Baseado em Problemas (ABP), por meio de uma perspectiva construtivista piagetiana. A pesquisa aplicou um questionário a 44 alunos matriculados na disciplina, concluindo que o ensino em pequenos grupos facilita a aprendizagem, devendo inclusive, ser estendido para outras disciplinas do curso. Os autores também sugerem formação teórica sólida dos professores para atuarem com esta abordagem de ensino, através do construtivismo. Os dados relevam que o método pode ser utilizado com evidente sucesso, até mesmo nos ambientes em que predominam os métodos tradicionais de ensino.

Azevedo et ál. (2017) buscaram identificar conhecimentos, habilidades e atitudes desenvolvidas pelos discentes de Contabilidade por meio da aprendizagem baseada em projetos (ABP), na disciplina Orçamento Empresarial. Os autores constataram que as habilidades apresentaram mais desenvolvimento nos elementos como trabalho em equipe, planejamento 
e na visão sistêmica, enquanto que nas atitudes destacaram-se o comprometimento, a pro atividade e o respeito pela opinião dos outros. As conclusões sugerem que a utilização da técnica pode ser considerada como positiva.

Enquanto, de Vargas et ál (2020) aplicaram o PBL em uma turma de ciências contábeis de uma instituição privada de ensino superior, revelando que na opinião dos alunos, a técnica propriciou melhor entendimento e a experiência desenvolvida os aproximou mais da prática de trabalho.

\section{Procedimentos metodológicos}

Para analisar se o uso da aprendizagem baseada em problemas auxilia o estudante no desenvolvimento e construção do conhecimento, através da assimilação, opotou-se pelo desenvolvimento de um estudo com orientação qualitativa. Quanto a estratégia da pesquisa, foi realizado um estudo de caso, buscando-se, compreender como a utilização de uma técnica de ensino ativa, a aprendizagem baseada em problemas (que possui um roteiro), pode auxiliar no desempenho e na construção do conhecimento. A pesquisa foi desenvolvida através da aplicação de uma atividade (mini caso), baseada na resolução de um problema real, que pode surgir na prática empresarial, na disciplina Estrutura das Demonstrações Contábeis, com estudantes do curso de Ciências Contábeis, de uma Instituição Federal de Ensino Superior (IFES) que estão cursando o $4^{\circ}$ semestre. Na ocasião da investigação, 37 estudantes estavam matriculados na disciplina, dos quais 29 compuseram a amostra estudada.

A aplicação da técnica de Aprendizagem baseada em Problemas ocorreu durante seis aulas, cada uma com duração de 50 minutos, nas quais foi trabalhado o conteúdo relacionado a Demonstração do Valor Adicionado (DVA). A primeira e a segunda aulas foram expositivas e exploraram os conceitos referentes à DVA, segundo o conteúdo vigente e estabelecido no pronunciamento técnico, do Comitê de Pronunciamentos Contábeis CPC 09, que trata da referida demonstração contábil.

Após as aulas expositivas sobre o conteúdo e a resolução de exercícios, aplicou-se um questionário para identificar o conhecimento prévio dos alunos sobre os conceitos abordados, necessários para a resolução do problema que foi apresentado na etapa seguinte, pois segundo Rosa (1996), no processo de ensino e aprendizagem, desenvolvido através da perspectiva construtivista, é necessário considerar o conhecimento prévio do aluno sobre o assunto.

Conseguinte as aulas expositivas, a resolução de exercícios e aplicação do primeiro questionário, os alunos foram separados em 5 grupos de até 6 pessoas. Cada grupo escolheu um estudante para desempenhar as funções de secretário (relator das discussões), líder (motivar e mediador), porta-voz (voz do grupo) e demais membros do grupo (participantes/debatedores), iniciando aplicação do PBL. 
Para classificar as respostas apresentadas nos questionários, foram utilizadas definições operacionais para especificar a medição das variáveis, conforme indica Bandeira (2014). Segundo Martins e Pelissaro (2005), estas definições operacionais constituem uma ponte interpretativa entre os conceitos e as observações realizadas.

Para aplicação da técnica, foi seguido o roteiro de sete passos sugerido por Leal et ál. (2017), que contempla: (1) apresentação da situação problema: nesta etapa foi entregue aos grupos uma DVA das Lojas Renner relativa aos anos de 2015 e 2016 e questionou-se "Como a empresa poderia melhorar a remuneração dos capitais próprios?"; (2) identificação do problema: neste momento os grupos iniciaram suas discussões sobre como resolver o problema proposto, através da análise da demonstração; (3) discussão dos conhecimentos prévios do grupo sobre a situação problema: os grupos levantaram hipóteses baseadas nos conhecimentos prévios que possuíam sobre o assunto; (4) resumir a discussão: os estudantes relembraram os problemas listados e levantaram hipóteses e diagnósticos, os quais foram registrados pelo secretário; (5) identificar pontos obscuros e formar o conjunto de assuntos/temas que precisam ser estudados: os grupos realizaram um levantamento sobre quais conteúdos precisasavam ser pesquisados para que os perimitissem solucionar o problema apresentado, estas questões apontadas pelo grupo foram distribuídas entre os membros, para pesquisa; (6) estudo ou busca de informações de forma individual, para posterior confrontação: esta etapa de pesquisa foi realizada individualmente pelos estudantes fora do período das aulas; (7) todos os membros trazem as informações coletadas e o grupo discute e identifica o que pode ser útil para resolver o problema: esta etapa se constituiu na última aula, ocasião em que o porta-voz de cada grupo apresentou as possíveis resoluções ao problema.

Durante a realização das 7 etapas os estudantes puderam contar com a mediação do professor (titular da disciplina) e de um mestrando do programa de Pós-Graduação em Contabilidade. Após a finalização destes passos, os estudantes obtiveram um feedback das propostas apresentadas e ao final das discussões, foi aplicado um segundo questionário, além de uma avaliação e auto-avaliação da atividade.

Os questionários serviram como instrumento de avaliação do conhecimento, através da análise do domínio do conteúdo adquirido, buscando-se verificar o conteúdo assimilado através da aula expositiva e após aplicação do PBL, bem como, se houve um processo de adaptação que levou a acomodação ou assimilação deste conteúdo. Esta verificação ocorreu por meio de comparação das respostas tabuladas, as quais não possuíam a identificação do estudante, pois serviram de base para uma "avaliação/verificação" de quais conhecimentos novos foram construídos (assimilados) de maneira geral. Quanto às habilidades e atitudes, estas foram analisadas através da avaliação e auto-avaliação realizada pelos estudantes, conforme ilustra a Figura 1. 
Figura 1: Métodos de Avaliação

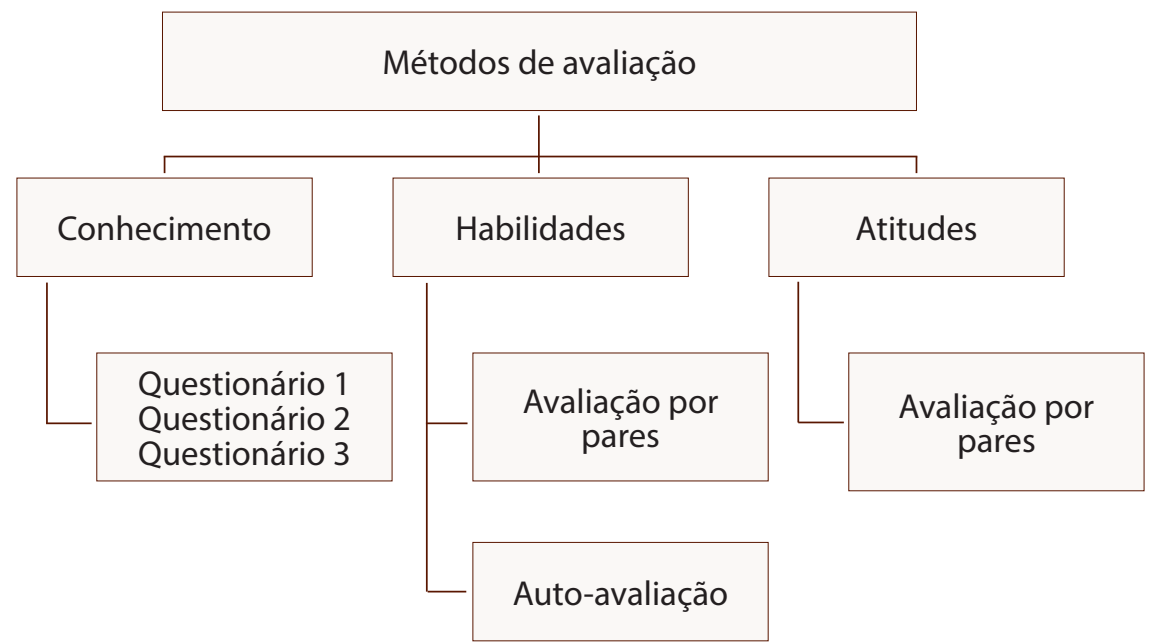

Nota: Elaborado pelos autores.

Diante da visão de que o processo de ensino aprendizagem é construído pelo indivíduo, baseando-se na assimilação e acomodação de significados (Piaget, 1970), esta pesquisa aplicou a técnica aprendizagem baseada em problemas para o ensino da DVA, verificando inicialmente o conhecimento prévio dos estudantes sobre o assunto, para que durante e após a execução da técnica, se pudesse confrontar o desenvolvimento (conhecimento) assimilado, resultante de um processo de adaptação.

Assim, a realização da aula expositiva e a resolução de exercício foram utilizadas como um esquema tradicional de ensino, conhecido pelo estudante, permitindo assimilação do conteúdo, visto que este método é usual e faz parte da sua rotina, com a intenção de facilitar a sua adaptação ao assunto apresentado. Posteriormente, este estudante foi submetido a uma nova situação, através da aprendizagem baseada em problemas, que o colocou frente a uma situação desconhecida, causando um desequilíbrio, no qual o aluno teve que modificar seu esquema em busca da acomodação ou assimilação (solução), para construir, desta maneira, um novo conhecimento.

O estudo limitou-se a uma turma do curso de Ciências Contábeis, de uma IFES, buscando aplicar e avaliar apenas o uso da técnica de ensino, aprendizagem baseada em problemas, e verificar sua contribuição para a construção (assimilação) do conhecimento.

\section{Análise e discussão dos resultados}

Conforme destacado na seção 3, inicialmente aplicou-se um questionário após a aula expositiva conceitual e resolução de exercício, buscando-se identificar os conhecimentos 
prévios adquiridos. O instrumento continha quatro questões sobre a DVA, e buscava verificar se o conteúdo exposto foi assimilado, conforme Tabela 1.

Tabela 1: Conhecimento prévio dos estudantes

\begin{tabular}{|c|c|c|c|c|c|}
\hline Questões & $\begin{array}{l}\text { Certa - } \\
\text { Completa }\end{array}$ & $\begin{array}{l}\text { Parcialmente Certa - } \\
\text { Incompleta }\end{array}$ & Errada & $\begin{array}{c}\text { Não } \\
\text { respondeu }\end{array}$ & Total \\
\hline $\begin{array}{l}\text { Os insumos adquiridos por terceiros estão } \\
\text { representados na DVA através de: CPV, Materiais, } \\
\text { Energia, serviços de terceiros, Perda/recuperação } \\
\text { de ativo, entre outros }\end{array}$ & 17 & 0 & 11 & 1 & 29 \\
\hline O que é apurado através da DVA? & 10 & 16 & 2 & 1 & 29 \\
\hline $\begin{array}{l}\text { Através da análise da DVA quais são as contas } \\
\text { que contribuem para a composição do valor } \\
\text { adicionado? }\end{array}$ & 4 & 22 & 0 & 3 & 29 \\
\hline
\end{tabular}

Nota: Dados da pesquisa. Elaborado pelos autores.

Referente aos insumos de terceiros, percebe-se que 17 estudantes assimilaram o conteúdo, (marcando certo como resposta), 11 permaneceram na condição em que se encontravam antes da aula, ou seja, não assimilaram um dado novo, continuando no esquema de acomodação. Considera-se também que o estudante que não respondeu a questão não absorveu a informação.

A segunda questão apresentada fez referência ao conteúdo que é apurado por meio da demonstração. Observa-se, portanto, que, esta pesquisa utilizou definições operacionais que auxiliaram a classificação das respostas como certa e errada. Como resposta certa, compreendeuse por aquela emitida de maneira completa, ou seja, evidenciando a riqueza gerado e sua distribuição. Cabe salientar, que nesta análise algumas respostas foram consideradas certas sem necessariamente terem utilizado os mesmos termos empregados pelos autores de base do conteúdo, pois a intenção desta pesquisa não foi verificar a capacidade de repetição/ memorização dos estudantes, visto que na percepção construtivista o que é estimulado/ esperado é a capacidade de reflexão e compreensão do conteúdo, conforme indica Piaget (1970). Quanto ao item considerado parcialmente certo, o mesmo foi utilizado para agrupar aquelas respostas que esclareceram apenas parte do questionamento.

Conforme exposto na Tabela 1, 10 estudantes assimilaram o conteúdo questionado, 16 construíram um conhecimento parcial sobre o assunto, apresentando respectivamente respostas como: A geração de riqueza e sua distribuição e $O$ Valor adicionado com as atividades da empresa. Estes resultados são positivos, visto que as respostas de apenas 2 estudantes eram inconsistentes, ou seja, respostas fora do contexto questionado, como: Na DVA você consegue verificar e analisar onde há mais entrada e mais saída de dinheiro e um estudante não respondeu a pergunta. 
http://doi.org/10.15359/ree.24-2.19

ROR: https://ror.org/01t466c14 Universidad Nacional, Costa Rica

http://www.una.ac.cr/educare

educare@una.cr

No terceiro questionamento, buscou-se verificar o conhecimento construído a respeito dos elementos que contribuem para a formação do valor adicionadoNesta questão também foram utilizados os mesmos critérios de certo e parcialmente certo. Desta forma, considerouse como positiva a construção do conhecimento dos estudantes quanto aos elementos que contribuem para a composição do valor adicionado, pois 4 estudantes responderam de maneira completa, listando todos os elementos que de forma geral, integram a composição do valor integrado, como as contas de receitas, variações das provisões, benefícios, insumos, depreciação e transferências recebidas e 22 estudantes responderam a questão de forma parcial, contemplando alguns elementos desta composição. Somente 3 estudantes não responderam este item e não houve resposta incorreta.

Quanto à última questão constante no $1^{\circ}$ questionário, foram solicitadas sugestões de possíveis maneiras de melhorar a remuneração de capitais próprios, conforme Tabela 2.

Tabela 2: Sugestões sobre o melhoramento da remuneração dos capitais próprios

\begin{tabular}{cc}
\hline Que sugestões você teria para melhorar a remuneração de capitais próprios? & No de estudantes \\
\hline $\begin{array}{l}\text { Proposta fundamentada } \\
\text { Proposta vaga }\end{array}$ & 12 \\
Proposta incoerente & 8 \\
Não respondeu & 29 \\
\hline Total & 29 \\
\hline
\end{tabular}

Nota: Dados da pesquisa. Elaborado pelos autores.

Como proposta fundamentada, entende-se, através da definição operacional desta pesquisa, aquela que apresenta argumentos possíveis, como por exemplo, uma das respostas apresentadas: Aumentar a remuneração de comissão, isso incentivaria funcionários a venderem mais, aumentando assim a receita e por consequência a remuneração de capitais próprios (Estudante 1). Quanto à resposta vaga, foram assim caracterizadas aquelas que apenas emitiram uma resposta sem contextualizá-la, sem argumentação, como a sugestão: Aumento das receitas (Estudante 5). A resposta classificada como incoerente, foi: Mais investimentos na empresa e investimentos em outras a fim de captar mais lucro (Estudante 8), pois não apresenta argumentos que a sustente. Para este questionamento, 8 estudantes não indicaram resposta, inferindo-se que esta temática não foi absorvida a ponto de proporcionar reflexões. 
Finalizando esta etapa, iniciou-se a aplicação do PBL, com os estudantes debatendo, trocando ideias, experiências e realizando uma pesquisa. Segundo Freire (1996) quando o aluno vivencia a prática de resolução de problemas, ele está atuando de forma ativa.

A intenção desta proposição foi procurar solucionar a problemática apresentada, referente à DVA das Lojas Renner, contendo os dados de 2015 e 2016, sobre: “Como as Lojas Renner poderiam melhorar a remuneração dos capitais próprios?"

Conforme esclarecido na seção 3, este estudo seguiu os sete passos sugeridos por Leal et ál. (2017). Após a conclusão da atividade, foi aplicado um segundo questionário com a intenção de verificar se o uso do PBL auxiliou na construção do conhecimento, ou seja, se o estudante submetido a técnica atingiu uma assimilação do conteúdo, agregando uma nova informação a sua estrutura cognitiva.

As questões contidas no segundo instrumento eram semelhantes às contidas no primeiro, conforme Tabela 3.

Tabela 3: Conhecimento após o uso da técnica

\begin{tabular}{|c|c|c|c|c|c|}
\hline Questões & $\begin{array}{l}\text { Certa - } \\
\text { Completa }\end{array}$ & $\begin{array}{l}\text { Parcialmente Certa - } \\
\text { Incompleta }\end{array}$ & Errada & $\begin{array}{l}\text { Não } \\
\text { respondeu }\end{array}$ & Total \\
\hline $\begin{array}{l}\text { As receitas de venda de mercadorias, produtos } \\
\text { e serviços de uma indústria devem incluir, na } \\
\text { demonstração do valor adicionado, os valores dos } \\
\text { tributos incidentes sobre as referidas receitas }\end{array}$ & 20 & 0 & 1 & 0 & 21 \\
\hline O que é evidenciado pela DVA? & 8 & 11 & 0 & 2 & 21 \\
\hline $\begin{array}{l}\text { Através da análise da DVA quais elementos } \\
\text { representam o destino do valor adicionado? }\end{array}$ & 14 & 4 & 0 & 3 & 21 \\
\hline
\end{tabular}

Nota: Dados da pesquisa. Elaborado pelos autores.

Na execução desta etapa, realizada após a aplicação do PBL, contou-se com a presença de 21 estudantes, que compareceram na última aula. Através do questionamento direto (certo ou errado), referente à composição da receita de venda utilizada na DVA, percebe-se que 20 estudantes acertaram a questão, o que sugere um significativo progresso na construção do conhecimento, evidenciando que apenas um estudante errou a resposta da questão. Comparando-se proporcionalmente este questionamento com a primeira questão realizada, 
http://doi.org/10.15359/ree.24-2.19

ROR: https://ror.org/01t466c14 Universidad Nacional, Costa Rica

http://www.una.ac.cr/educare

educare@una.cr

sem o uso do $\mathrm{PBL}$, percebe-se que a assimilação demonstrada na Tabela 1 (aula expositiva mais resolução de exercício) foi de $58,62 \%$ pelos estudantes, enquanto que com o uso PBL esta assimilação foi de 95,23\%, conforme Tabela 3, indicando assim, um crescimento significativo com o uso da metodologia ativa.

Segundo Piaget (1970), o processo educacinal proporcionado através de métodos ativos, gera benefícios como a compreensão do indivíduo. Ratificando este argumento, Rodrigues e Araujo (2007) afirmam que o método estimula a aprendizagem, visto que os estudantes apresentam maior assimilação do conteúdo.

O segundo questionamento realizado nesta fase referiu-se a evidenciação da DVA. Através dos critérios operacionais estabelecidos, foram obtidas 8 respostas certas, 11 parcialmente certas, nenhuma considerada errada e 2 estudantes não responderam. Comparando-se estes resultados com os listados na Tabela 1, percebe-se no questionamento inicial que dos 29 respondentes, 26 responderam de forma certa ou parcialmente certa, ou seja, cerca de 89,65\% dos estudantes compreenderam total ou parcialmente o conteúdo ministrado. Este resultado foi semelhante ao apresentado na Tabela 3, visto que dos 21 respondentes, 19 apresentaram uma resposta certa ou parcialmente certa, representando $90,47 \%$. Portanto, este item não releva uma significância quanto ao uso do PBL, pois os resultados apontados se assemelham aos da aula expositiva mais a resolução de exercícios.

A terceira questão apresentada, no segundo questionário, buscou verificar se os estudantes conseguiram captar para onde o valor adicionado no exercício é destinado, neste sentido, perguntou-se quais elementos representavam esta destinação.Na etapa inicial executada por meio do questionário 1, buscou-se compreender como os estudantes entenderam a formação do valor adicionado, enquanto neste segundo momento, procurou-se verificar se estes estudantes conseguiram entender como o valor adicionado é distribuído. Na Tabela 1, evidenciou-se que 4 pessoas responderam a questão de maneira completa e 22 de forma parcial. No segundo questionário (Tabela 3), após o PBL, das 21 respostas obtidas, 14 pessoas responderam a questão de forma completa e 4 parcialmente. Estes dados revelam que o conteúdo foi assimilado pela maioria dos participantes, apresentando uma ampliação nas respostas completas, com o uso do PBL.

Quanto ao último elemento questionado, buscou-se verificar as sugestões dos estudantes quanto a uma forma de melhorar a remuneração dos capitais próprios, exatamente da mesma forma com que foi elaborada antes do PBL. Os dados revelados após a aplicação do método permitem inferir que houve avanço na construção do conhecimento destes estudantes, visto que na primeira aplicação, 8 estudantes responderam a questão de forma fundamentada, enquanto 12 apresentaram propostas vagas e 8 não responderam, já no segundo momento, as evidências foram mais positivas, em termos de consolidação do conhecimento, pois observa-se que 13 estudantes responderam de forma fundamentada, 6 com propostas vagas, e apenas 2 não responderam.

16 Michele Urrutia-Heinz, Alexandre Costa-Quintana y Ana Paula Capuano-da Cruz

Los artículos de la Revista Electrónica Educare del Centro de Investigación y Docencia en Educación de la Universidad Nacional, Costa Rica, se comparten bajo términos de la Licencia Creative Commons: Reconocimiento, № Comercial, Sin Obra Derivada 3.0 Costa Rica. Las autorizaciones adicionales a las aquí delimitadas se pueden obtener en el correo: educare@una.cr 
As respostas classificadas como fundamentada apresentaram sugestões possíveis dentro contexto analisado, como: "Aumento de receitas, tentar a diminuição de carga tributária (incentivos fiscais), tentar diminuir os aluguéis" e como proposta vaga: "Aumento das receitas".

Portanto, conforme indicam Caron e Bolsanello (2017) a aprendizagem baseada em problemas, por meio de um viés construtivista, pode ser estendida com sucesso, para cursos além da medicina, conforme percebe-se neste estudo para o curso de Ciências Contábeis, através da ampliação no número de respostas fundamentadas (assimiladas) com o uso do PBL.

Outra preocupação desta pesquisa, foi buscar identificar às habilidades e atitudes constituídas durante a aplicação do PBL, através da avaliação e auto-avaliação realizada pelos estudantes, por meio da aplicação de um formulário que continha assertivas relacionadas às habilidades e atitudes, para as quais os estudantes indicaram seu posicionamento: (1) concordo plenamente; (2) concordo parcialmente; (3) não concordo; (4) discordo parcialmente e (5) discordo totalmente, conforme Tabela 4.

Tabela 4: Avaliação pelos pares - Habilidades

\begin{tabular}{lcccccc}
\hline \multicolumn{1}{c}{ Questões avaliadas } & Nota & Grupo 1 & Grupo 2 & Grupo 3 & Grupo 4 & Grupo 5 \\
\hline $\begin{array}{l}\text { A. O grupo desenvolveu buscas por soluções } \\
\text { de maneira criativa e inovadora. }\end{array}$ & Nota & $1-2-1-1-1-$ & $1-1-1-2-1-1-$ & $1-1-1-$ & $1-1-5-2-2-$ & $3-2-$ \\
$\begin{array}{l}\text { B. A comunicação entre os componentes do } \\
\text { grupo foi boa }\end{array}$ & Nota & $1-1-2-2-1-$ & $1-1-2-1-1-1-$ & $1-1-1-$ & $1-1-4-1-1-$ & $2-3-$ \\
$\begin{array}{l}\text { C. O planejamento proposto pelo grupo } \\
\text { ocorreu como o esperado }\end{array}$ & Nota & $2-1-2-1-1-$ & $1-2-1-1-1-1-$ & $1-2-1-$ & $1-1-4-2-2-$ & $2-3-$ \\
$\begin{array}{l}\text { D. O grupo conseguiu atuar de maneira } \\
\text { integrada. }\end{array}$ & Nota & $2-2-2-2-1$ & $2-1-1-2-1-2-$ & $1-1-1-$ & $1-1-4-2-1-$ & $2-2-$ \\
$\begin{array}{l}\text { E. O grupo conseguiu elaborar soluções } \\
\text { para resolver o problema. }\end{array}$ & Nota & $1-2-1-1-1-$ & $1-1-2-1-2-1-$ & $1-1-1-$ & $1-1-4-1-1-$ & $2-2-$ \\
\hline \begin{tabular}{l} 
Quantidade de estudante por grupo \\
\hline
\end{tabular} & & 5 & 6 & 3 & 5 \\
\hline
\end{tabular}

Nota: Dados da pesquisa. Elaborado pelos autores.

Através da Tabela 4 pode-se verificar que a maioria dos estudantes entendeu que o grupo buscou soluções ao problema apresentado de forma criativa, desenvolvendo boa comunicação, executando o planejamento de acordo com o proposto, trabalhando de forma integrada e apresentando sugestões para solucionar o problema. Estas inferências estão embasadas na maioria das respostas que atribuíram à nota concordo totalmente (1) e concordo parcialmente (2), com exceção do grupo 5, que possuía 6 integrantes, dos quais apenas 2 compareceram 
http://doi.org/10.15359/ree.24-2.19

ROR: https://ror.org/01t466c14 Universidad Nacional, Costa Rica

http://www.una.ac.cr/educare

educare@una.cr

na última aula, ou seja, aula em que foi apresentado e discutido soluções para o problema, sugerindo assim que o grupo 5 não atuou de forma integrada, como os demais grupos.

Este resultado, com exceção ao grupo 5, vai ao encontro do estudo de Cezar et ál (2010), que afirmam que através de metodologias ativas é possível tornar o aprendizado mais dinâmico e integrado. Neste contexto também foi realizada uma auto-avaliação das habilidades, com a intenção de verificar como o estudante se percebe diante uma atividade em grupo, conforme Tabela 5.

Tabela 5: Auto-avaliação - Habilidades

\begin{tabular}{|c|c|c|c|c|c|c|}
\hline Questões avaliadas & Nota & Grupo 1 & Grupo 2 & Grupo 3 & Grupo 4 & Grupo 5 \\
\hline $\begin{array}{l}\text { A. Busquei solucionar o problema de } \\
\text { maneira criativa e inovadora. }\end{array}$ & Nota & $2-2-1-1-1-$ & $1-3-2-2-2-2-$ & $2-2-1-$ & $2-1-2-2-5-$ & $2-2-$ \\
\hline $\begin{array}{l}\text { B. Consegui desenvolver uma boa } \\
\text { comunicação com os demais } \\
\text { componentes do grupo }\end{array}$ & Nota & $2-2-2-1-1-$ & $1-2-2-1-1-1-$ & $1-2-1-$ & $1-1-2-1-1-$ & $5-5-$ \\
\hline $\begin{array}{l}\text { C. Cumpri a tarefa planejada que ficou sob a } \\
\text { minha responsabilidade }\end{array}$ & Nota & $2-1-1-1-1-$ & $1-2-1-1-1-1-$ & $1-2-1-$ & $2-1-1-2-2-$ & $1-1-$ \\
\hline D. Consegui trabalhar integrado (a) ao grupo & Nota & $2-1-1-2-1-$ & $1-2-1-2-1-1-$ & $1-2-1-$ & $1-1-2-2-1-$ & $1-2-$ \\
\hline E. Sugeri soluções para resolver o problema. & Nota & $2-1-1-2-1-$ & $1-2-2-1-1-1-$ & $1-2-1-$ & $2-1-1-2-1-$ & $1-1-$ \\
\hline Quantidade de estudante por grupo & & 5 & 6 & 3 & 5 & 2 \\
\hline
\end{tabular}

Nota: Dados da pesquisa. Elaborado pelos autores.

Complementarmente, buscou-se avaliar as habilidades desenvolvidas pelo grupo e pelo indivíduo, tais como: criatividade e inovação; comunicação; planejamento; integração; e solução de problema. Ao realizarem uma auto-avaliação, a maioria dos estudantes concordou (parcial ou totalmente), que houve esforço para solucionar o problema e integração. Comparando-se o resultado da avaliação pelos pares com a auto-avaliação, por exemplo da questão $A$, percebese que, ao avaliarem o grupo, a maioria dos estudantes manifestou concordância quanto a afirmativa, revelando que faltou mais esforço individualmente do que por parte do grupo de forma geral.

Quanto as atitudes desenvolvidas pelo grupo, foram avaliados: comprometimento; flexibilidade; interesse; troca de experiência profissional; colaboração, cooperação e respeito, conforme Tabela 6. 
Tabela 6: Avaliação pelos pares - Atitudes

\begin{tabular}{lcccccc}
\hline Questões avaliadas & Nota & Grupo 1 & Grupo 2 & Grupo 3 & Grupo 4 & Grupo 5 \\
\hline $\begin{array}{l}\text { A. O grupo desenvolveu as tarefas de } \\
\text { maneira colaborativa e respeitosa }\end{array}$ & Nota & $1-1-1-1-$ & $1-1-1-1-1-1-$ & $1-1-1-$ & $1-1-2-2-1-$ & $2-2-$ \\
$\begin{array}{l}\text { B. O grupo apresentou comprometimento } \\
\text { no desenvolvimento da atividade }\end{array}$ & Nota & $1-1-2-1-$ & $2-1-1-2-1-1-$ & $1-2-2-$ & $1-1-2-2-2-$ & $4-2-$ \\
$\begin{array}{l}\text { C. O grupo demonstrou flexibilidade ao } \\
\text { distribuir as tarefas }\end{array}$ & Nota & $2-1-2-1-$ & $2-1-1-1-1-1-$ & $1-1-2-$ & $1-1-2-2-1-$ & $4-2-$ \\
$\begin{array}{l}\text { D. } \begin{array}{l}\text { Todos os integrantes demonstram } \\
\text { interesse }\end{array} \\
\begin{array}{l}\text { E. A atividade proporcionou troca de } \\
\text { experiência entre os membros do grupo }\end{array}\end{array}$ & Nota & $2-2-3-1-$ & $2-2-2-2-2-1-$ & $1-1-2-$ & $1-1-2-2-1-$ & $4-3-$ \\
\hline \begin{tabular}{l} 
Quantidade de estudante por grupo \\
\hline
\end{tabular} & Nota & $2-1-1-1-$ & $2-2-1-2-2-1-$ & $1-1-1-$ & $1-1-2-2-2$ & $2-2-$ \\
\hline
\end{tabular}

Nota: Dados da pesquisa. Elaborado pelos autores.

Conforme a Tabela 6, percebe-se que todos os estudantes concordaram plena ou parcialmente que o grupo executou as tarefas de maneira colaborativa e respeitosa. Cumpre salientar que, na avaliação das atitudes, um dos estudantes (grupo 1) não respondeu as questões propostas.

Quanto à avaliação do comprometimento referente ao desenvolvimento da tarefa, obtevese uma resposta indicativa de total discordância, enquanto os demais concordaram plena ou parcialmente com a segunda afirmação, no entanto, os demais participantes assinalaram que houve comprometimento.

Analisando-se a flexibilidade dos integrantes, na distribuição das tarefas, nota-se, que como na avaliação do comprometimento, um estudante discordou totalmente, enquanto os demais concordaram que houve flexibilidade na escolha das tarefas. Quanto a demonstração de interesse pela atividade, dois estudantes não concordaram e um discordou totalmente com a afirmação, enquanto os demais (17 estudantes) concordaram plena ou parcialmente, sugerindo que a maioria entendeu que houve interesse por parte dos colegas com atividade.

A última afirmativa apresentada referiu-se a troca de experiência desenvolvida durante a atividade. Os achados demonstraram que todos os estudantes reconheceram que houve troca de experiência. 
http://doi.org/10.15359/ree.24-2.19

ROR: https://ror.org/01t466c14 Universidad Nacional, Costa Rica

http://www.una.ac.cr/educare

educare@una.cr

\section{Considerações finais}

Por meio deste estudo buscou-se identificar como o uso da aprendizagem baseada em problemas pode auxiliar na construção do conhecimento (assimilação do conteúdo), visto que a Teoria da Equilibração compreende que o conhecimento é construído pelo sujeito através de sua interação com o mundo, considerando-o como um agente ativo neste processo. Assim, este estudo parte da premissa que o PBL que é uma ténica de ensino ativa, que baseia-se na aprendizagem através da resolução de problemas e que busca solucionar um problema real ou simulado, a partir de um contexto (de Souza, \& Dourado, 2015).

Os achados desta pesquisa comprovam que o PBL auxilia na construção do conhecimento, visto que através dele é possível verificar um melhor desempenho do estudante com o conteúdo apresentado, ou seja, uma maior assimilação do conteúdo, inferindo que houve maior adaptação entre o conteúdo desenvolvido com o uso do PBL do que com a aula expositiva mais a resolução de exercício. Além de gerar benefícios como a integração entre os estudantes, troca de experiência e o desenvolvimento da habilidade como a busca de soluções - elementos essenciais à profissão contábil. Estes resultados assemelham-se ao estudo de Azevedo et ál. (2017), que constataram em sua pesquisa, através do uso da aprendizagem baseada em projetos, que também é uma técnica ativa e similar ao PBL, com estudantes de Contabilidade, que a metodologia ativa desenvolve habilidades como trabalho em equipe, assim como o comprometimento e respeito pela opinião alheia.

Hendry et ál. (2017) destacam que o uso da aprendizagem baseada em problemas e em projetos, além de outras técnicas de ensino construtivas, devem ser consideradas metodologias eficazes para aquisição de conhecimento, pois permitem um maior desenvolvimento de habilidades. Neste sentido, esta pesquisa ratificando a afirmação de Hendry et ál. (2017), relevou, para este estudo, que o uso da aprendizagem baseada em problemas permitiu o desenvolvimento da habilidade de busca por soluções, bem como auxiliou no desenvolvimento cognitivo.

Segundo Moretto (2003), é preciso transformar em ação a interação em sala de aula para que a mesma proporcione ações construtivistas. Neste contexto, infere-se que a aplicação do PBL pode ser considerada como uma técnica indicada, que auxilia no desempenho do estudante frente a apresentação de um novo conteúdo, visto que na aplicação desta pesquisa a mesma proporcionou uma assimilação superior à aula expositiva mais resolução de exercícios, demonstrando que a experiencia melhora a compreensão. Desta forma, é possível deduzir, que o PBL auxilia no desempenho e na construção do conhecimento, tendo em vista a ampliação do número de estudantes, que após a sua aplicação, assimilaram o conteúdo apresentado sobre a DVA e construíram explicações próprias. Segundo Libâneo (2014), uma aprendizagem é considerada de qualidade quando desenvolve raciocínio próprio, permitindo ao estudante explicar uma ideia através das suas próprias palavras.

A aplicação do PBL possibilitou aos estudantes participantes deste estudo, a troca de experiências, além de simular uma situação real, que permitiu aos mesmos a experiência com uma situação prática. Elemento essecial, segundo o pensamento de Jumaat et ál. (2017), de que

\footnotetext{
20

Michele Urrutia-Heinz, Alexandre Costa-Quintana y Ana Paula Capuano-da Cruz
}

Los artículos de la Revista Electrónica Educare del Centro de Investigación y Docencia en Educación de la Universidad Nacional, Costa Rica, se comparten bajo términos de la Licencia Creative Commons: Reconocimiento, № Comercial, Sin Obra Derivada 3.0 Costa Rica. Las autorizaciones adicionales a las aquí delimitadas se pueden obtener en el correo: educare@una.cr 
a aprendizagem é um proceso baseado na experiencia. Segundo Dewey (1910), a educação tem como objetivo desenvolver a inteligência de forma independente e eficaz, cabendo ao educador fornecer estímulos para os alunos através das atividades que proporcionem a experiência.

As práticas educacionais centralizadas no aluno promovem a construção do conhecimento, auxiliando no desenvolvimento de habilidades como falar com criatividade, analisar e sintetizar informações (Grabinger et ál., 1997). Neste sentido, os autores salientam a importância de inserir no ambiente acadêmico, questões do campo de trabalho, para que estas habilidades de construção do conhecimento e as atividades de resolução de problemas tornem o ambiente mais abrangente. Os dados encontrados neste estudo demonstram que os estudantes assimilaram mais o conteúdo, através do ambiente promovido pela aprendizagem baseada em problemas, além de atuar de maneira comprometida e colabativa. Segundo Piletti, \& Rossato (2018) quando o sujeito se percebe eficaz tende a ter construir suas ações de forma mais efetiva.

Sugere-se para pesquisas futuras a utilização de outras técnicas, embasadas na visão construtivista, que possam ser aplicadas aos estudantes de Ciência Contábeis, com a intenção de identificar se as mesmas auxiliam no desempenho e construção do conhecimento, através da assimilação do conteúdo. Em adição, sugere-se a aplicação de uma pesquisa semelhante, que aplique a aprendizagem baseada em problemas a um grupo maior de estudantes e em outras disciplinas da área contábil.

\section{Referências}

Azevedo, Y. G. P., de Araújo, A. O., \& de Medeiros, V. C. (2017). Conhecimentos, habilidades e atitudes desenvolvidas pelos discentes de contabilidade através da Aprendizagem Baseada em Projetos. Contabilidade, Gestão e Governança, 20(1), 153-174. https://doi. org/10.21714/1984-3925 2017v20n1a9

Bandeira, M. (2014). Texto 9. Definição das variáveis e métodos de coleta de dados. Laboratório de Psicologia Experimental. https://www.ufsj.edu.br/portal2-repositorio/File/lapsam/ Metodo\%20de\%20pesquisa/Metodos\%20de\%20pesquisa\%202013/Texto 9 Definicoes das variaveis e metodo de coletas de dados.pdf

Becker, F. (1992). O que é construtivismo. Revista de educação AEC, 21(83), 7-15.

Becker, F. (2016). Educação e construção do conhecimento: Revista e Ampliada. Penso Edição.

Caron, C. R., \& Bolsanello, M. A. (2017). O ensino médico baseado em problemas: uma experiência construtivista. Imagens da Educação, 7(2), 54-63. https://doi.org/10.4025/imagenseduc. $\underline{\mathrm{v} 7 \mathrm{i} 2.36798}$

Cezar, P. H. N., Guimarães, F. T., Gomes, A. P., Rôças, G., \& Sequeira-Batista, R. (2010). Transição paradigmática na educação médica: um olhar construtivista dirigido à aprendizagem baseada em problemas. Revista Brasileira de Educação Médica, 34(2), 298-303. https://doi. org/10.1590/S0100-55022010000200015 
da Silva, C. E. (2015). Estudo da aplicação do Problem Based Learning (PBL) no ensino superior de contabilidade (Dissertação de Mestrado). Pontifícia Universidade Católica, São Paulo. https://tede2.pucsp.br/handle/handle/1610

de Carvalho, A. M. P, de Castro, R. S., Laburu, C. E., \& Mortimer, E. F. (1992). Pressupostos epistemológicos para a pesquisa em ensino de ciências. Cadernos de Pesquisa, 82, 85-89. https://dialnet.unirioja.es/servlet/articulo?codigo $=6208130$

de Matos, A. A. (2008). Fundamentos da Teoria Piagetiana: Esboço dos Fundamentos da Teoria Piagetiana: Esboço de Um Modelo. Revista Ciências Humanas, 1(1), 1-13. http://dx.doi. org/10.32813/2179-1120.2008.v1.n1.a192

de Vargas, S. B, Scherer, A.P.Z, \& Garcia, L. S. (2020). As metodologias ativas no ensino da contabilidade: relato de experiências na sala de aula/The active methodologies in acccounting education: report of experiences in the classroom. Brazilian Journal of Development, 6(1) 3885-3905. https://doi:10.34117/bjdv6n1-275

de Souza, S. C., \& Dourado, L. (2015). Aprendizagem baseada em problemas (ABP): um método de aprendizagem inovador para o ensino educativo. HOLOS, 5, 182-200. https://doi. org/10.15628/holos.2015.2880

Dewey, J. (1910). How we think. Boston. MA: D C Heath. https://doi.org/10.1037/10903-000

Freire, P. (1996). Pedagogia da autonomia. Saberes necessários à prática educativa (54th ed.). Paz e Terra.

Frezatti, F., Borinelli, M. L., Martins, D. B., \& Espejo, M. M. dos Santos. P. (2016). Análise do desempenho de alunos na perspectiva do CHA em disciplina utilizando PBL: o que significa a síntese? Revista de Contabilidade e Organizações, 10(26), 3-19. https://doi.org/10.11606/rco.v10i26.79588

Grabinger, S., Dunlap, J. C., \& Duffield, J. A. (1997). Rich environments for active learning in action: problem-based learning. Research in Learning Technology, 5(2), 5-17. https://doi. org/10.3402/rlt.v5i2.10558

Hendry, A., Hays, G, Challinor, K., \& Lynch, D. (2017). Undertaking educational research following the introduction, implementation, evolution, and hybridization of constructivist instructional models in an Australian PBL High School. Interdisciplinary Journal of ProblemBased Learning, 11(2), 1-16. https://doi.org/10.7771/1541-5015.1688

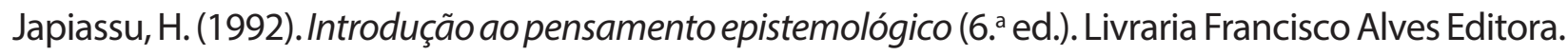

Jumaat, N. F, Tasir, Z., Halim, N. D. A., \& Ashari, Z. M. (2017). Project-Based Learning from Constructivism Point of View. Advanced Science Letters, 23(8), 7904-7906. https://doi. org/10.1166/asl.2017.9605

Leal, E. A., Miranda, G. J., \& Casa Nova, S. P. de C. (2017). Revolucionando a sala de aula: Como envolver o estudante aplicando as técnicas de metodologias ativas de aprendizagem. Atlas. 
Libâneo, J. C. (2014). O essencial da didática e o trabalho de professor:em busca de novos caminhos. Goiânia. https://docplayer.com.br/17119935-O-essencial-da-didatica-e-o-trabalho-deprofessor-em-busca-de-novos-caminhos.html

Martins, G. de A., \& Pelissaro, J. (2005). Sobre conceitos, definições e constructos nas Ciências Contábeis. Base-Revista de Administração e Contabilidade da Unisinos, 2(2), 78-84. https:// seer.uscs.edu.br/index.php/revista gestao/article/view/267

Moraes, R. (2000). É possível ser construtivista no ensino de ciências. Em R. Moraes (Org.), Construtivismo e ensino de ciências. Reflexões epistemológicas e metodológicas (3.a ed., pp. 103-130. EDIPUCRS.

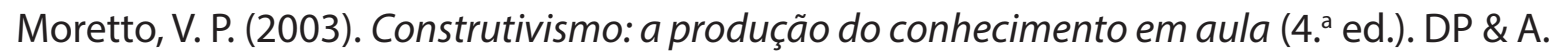

Munari, A. (2010). Jean Piaget. Fundação Joaquim Nabuco.

Piaget, J. (1970). Psicologia e pedagogia: a resposta do grande psicólogo aos problemas do ensino. Forense Universitária.

Piaget, J. (1975). Léquilibration des structures cognitives: problème central du développement. Presses universitaires de France.

Piaget, J. (1987). O nascimento da inteligência na Criança (4. a. ed.). LTC Editora.

Piaget, J. (1990). Epistemologia genética. Martins Fontes.

Piletti, N., \& Rossato, S. M. (2018). Psicologia do Desenvolvimento: da teoria do condicionamento ao construtivismo. Contexto.

Rodrigues, E. de A., \& Araújo, A. M. P. (2007). O ensino da contabilidade: aplicação do método PBL nas disciplinas de contabilidade em uma instituição de ensino superior particular. Revista de Educação, 10(10), 166-176. https://revista.pgsskroton.com.br/index.php/educ/ article/view/2150

Rosa, P. R. da S. (1996). A epistemologia genética de Piaget e o construtivismo. Em: P. R. da S., Instrumentação para o ensino de Ciências (pp. 1-21). UFMS.

Schmidt, H. G. (1983). Problem-based learning: rationale and descriptions. Medical Education, 17(1), 11-16. https://doi.org/10.1111/j.1365-2923.1983.tb01086.x

Stanley, T., \& Marsden, S. (2012). Problem-based learning: Does accounting education need it? Journal of Accounting Education, 30(3-4), 267-289. https://doi.org/10.1016/j. jaccedu.2012.08.005 